\title{
DYNAMIC LOADING OF TREES
}

\section{by Ken James}

\begin{abstract}
The dynamic forces on tree structures during periods of high winds is being studied in order to determine the loads on trees and the responses of the trees to those dynamic loads. Field measurements of dynamic forces on trees, branches, and cables have been conducted on urban trees in an attempt to quantify the magnitude of these forces and to provide a basis for evaluating tree stability. Equipment was constructed to measure the dynamic wind loads on tree trunks and branches in situ. This equipment is described, and results are presented which indicate that tree structure is loaded by highly variable wind gusts and responds by behaving in a complex dynamic manner, which minimizes the energy transfer from the wind to the tree structure. The dynamic response of the tree involves a complex interaction of the natural frequencies of each component of the tree, including the trunk, main branches, sub-branches, and smaller sections. A dynamic model of trees is presented and includes mass damping that minimizes the sway energies and combines with the drag forces of the canopy to help the tree cope with large wind forces. A discussion of windthrow and tree dismantling is presented, based on the information collected from these studies.

Key Words. Wind; stability; dynamic forces; loads; branches; cables; structure; frequencies; mass damping; drag; model; strength; bending; Young's modulus; windthrow; failure.
\end{abstract}

The information about tree structures has improved dramatically over the past decade and has provided a better understanding of how trees respond to the loads that are placed on them. These studies have led to the development of an "axiom of uniform stress" (Mattheck and Breloer 1994), which states that the growth of a tree is in response to the loads at a specific point. This finding leads to a conclusion that trees are optimized structures-neither too thin in any part, which would result in failure, nor unnecessarily thick, which would waste energy and nutrients by growing unnecessary wood.

The analysis based on the axiom of uniform stress is essentially a static analysis in which the loads and forces developed are the result of the static loads of the tree weight and possibly other static loads such as ice and snow. Wind loads have also been considered (Mattheck and Breloer 1994; Coutts and Grace 1995; Coder 2000), but the complexity of dynamic loading has usually resulted in applying a static-type analysis or in simplifying assumptions, such as treating the tree as an inverted pendulum structure and applying the appropriate mathematical formulae. Because wind loads are the largest loads on a tree, there is a need to apply the current knowledge on tree structures to this difficult area and examine the complex behavior of real trees in windstorms.

This paper describes a study of the loads on a tree in the field, during windstorms. The resulting data were analyzed to determine the exact nature of the wind loading and how the tree responds to these large dynamic forces. The analysis led to a dynamic model of a tree and its branches, which sway in a complex way to counteract each other so that dangerous sway motions in the tree are minimized. Equipment was developed to measure the loads on trees during windstorms, and some data are presented to support the discussion.

\section{TREE STRUCTURES AND THEIR LOADS}

Over its lifetime, which may be several hundred years, a tree must withstand all of the loads that are placed on it. An understanding of the magnitude and frequency of these loads and the responses of the tree is necessary if a full analysis of the tree structure is to be achieved.

When loads increase at a point on a tree, adaptive growth occurs at that point, and the tree attempts to relieve the stresses at that point. This finding was summarized in the axiom of uniform stress (Mattheck and Breloer 1994). The evidence can be seen in a number of ways. One is by examining a cut section of the tree and measuring the different thicknesses of growth rings at different parts of the tree section. The rings will be thicker on the side where the load has been greatest and thinner on the side where the load has been less. Another outward sign of adaptive growth is the appearance of buttressing at the base of a trunk or branch, which shows thickening by the addition of wood and thus localized strengthening to withstand the high loads. The load analysis using static forces is well advanced. The dynamic analysis of wind loading is a more complex situation and is yet to be quantified because of the difficulties of field measurement and the complex movements of trees.

The strategy used in this investigation was to measure actual loads on trees during winds and analyze the resulting information. This procedure is being performed over a lengthy time frame, and some results are reported in this paper. The other part of the strategy is to measure the strength of the tree and its limbs and the dynamic response of the tree.

A tree is a complex structure consisting of a trunk, side branches, sub-branches, and eventually small twigs and leaves. The strength of each structural member depends on three factors: the size of the cross section, the shape of the cross section, and the strength of the material (expressed as Young's modulus). 


\section{Size of the Cross Section}

The size of each part of the tree varies as it grows. The largest and strongest sections are the oldest, at the base of the trunk. Here static loads are the greatest. Farther up the trunk, loads are not as great, and the cross section gets smaller as the trunk tapers. New growth each year at the tips results in the smallest parts and logically the smallest loads.

\section{Shape of the Cross Section}

The shape of each part of the tree is determined by the adaptive growth. The load history of the tree can be determined by examining the width of growth rings. Examinations of even the largest trunks show that initial growth produces a circular cross section. This circular shape varies greatly as the section develops. A circular section is best adapted to torsional forces.

As a branch grows and becomes larger, the bending forces at the branch base also become larger. If bending forces are significant, an "I-beam" shape can develop, for which the greatest loads occur at the top (tension) and the bottom (compression) of the section. This change in shape is the tree's response to adaptive growth and results from the tree putting the wood where it is needed to take the load.

\section{Strength of the Material}

The strength of the woody material in the tree varies greatly, depending on where the wood is located and the age of the wood. The strength of a material is expressed as Young's modulus and is described in terms of force per unit area $\left(\mathrm{GN} \mathrm{m}^{-2}\right.$ or $\left.\mathrm{GPa}\right)$. The Young's modulus of whole sections of Scots pine (Pinus sylvestris) increased with tree age from about $1.7 \mathrm{GN} \mathrm{m}^{-2}$ at 7 years to $7.9 \mathrm{GN} \mathrm{m}^{-2}$ at 25 years and then remained substantially constant (Mencuccini et al. 1997). This increase indicates that younger wood is much more flexible than older wood. This study also concluded that heartwood contributed less than 50\% to the whole section's structural stiffness and that sapwood contributed most of the mechanical support.

When assessing the structural integrity of branches in a tree, it is therefore important to use the actual values of Young's modulus for the specific branch and not to make simplifying assumptions or use general figures. Doing so makes the task very difficult for a multi-limbed urban tree, but it is worth closer study of specific trees and species to provide indications of the magnitudes of strength.

\section{STATIC AND DYNAMIC LOADS}

The loads on trees and stresses developed in trunks and branches are a combination of

- tension (a pulling force)

- compression (a pushing force)

- bending (tension, compression, and shear)

- shear (a force causing layers to slide over each other)

- torsion (a twisting force)

- growth (a circumferential force)
All of the these loads can be applied as either static loads due to the weight of branches, foliage, snow, and ice, or as dynamic loads due to wind forces.

\section{Static Loads}

Static loads are constant loads in which there is little or no movement. As trees grow larger, static loads increase and there is a growth response as the tree adapts to these load increases (Mattheck and Breloer 1994). Static forces are always present and are part of the total forces when additional dynamic forces are applied. Static loads must be considered together with dynamic loads because it is the combination of both these loads that act on the tree. This paper deals primarily with dynamic loads, but that is not to say that static loads are ignored.

\section{Dynamic (Wind) Loads}

The largest loads on trees are dynamic loads caused by wind (Mattheck and Breloer 1994). Wind loads are periodic and produce a complex sway motion in trees. Multi-limbed urban trees may experience more sideways loading caused by wind than trees in forests, which are protected by their neighbors. For this reason, individual trees are being studied.

Wind loads on single-stemmed trees have been described (Mattheck and Breloer 1994; Wood 1995). For windthrow analysis, a simple wind force is used, and a static approach is taken to analyze the forces. This is a simple approach for estimating tree resistance to overturning and is a good first step.

For a more complete analysis of the dynamic behavior of trees, the complex motion of the tree swaying in the wind is often simplified using a conceptual model of a tree stem (Wood 1995) (without branches) and being considered as an upside-down pendulum (Coder 2000). This simplification is used to calculate a natural frequency for the sway period of a bare trunk only.

The dynamic forces in a complete tree structure have not yet been fully analyzed without major assumptions being made. These assumptions often ignore the effects of limbs and branches, the changes in material strength (Young's modulus) from the trunk to the outer limbs, and the effect of damping of the leaves and branches.

Wind comes in gusts, lasting for about 20 to $40 \mathrm{~s}$. There are many smaller gusts within these major gusts, and the effect is to exert a dynamically varying force on a tree canopy. The wind pushes on a tree canopy and can push upward on the branches pointing into the wind or sideways and upward on branches oriented at right angles to the wind (Shigo 1991). The branches of a tree respond with a complex sway motion in which the limbs move out of step with each other. This movement can be thought of as a de-tuned system that prevents the tree and its branches from developing dangerously large sway motions. It is a survival mechanism to ensure that a harmonic or pendulumlike sway is never developed. The tree does this to use up or dissipate the energy from the wind so that it is not transferred to the main trunk. 


\section{Damping}

The energy from the wind is dissipated by the tree, using a complex damping mechanism. The tree's response to wind is to minimize the energy transferred from the wind to the main structure of the trunk. The energy is dissipated partly by the leaf drag, partly by internal energy losses within the wood and root/soil system, and partly by the complex branch sway mechanism.

The sway motion is heavily damped by three main factors:

- hydraulic damping: aerodynamic drag forces of the foliage in the wind

- mass damping: the interaction of the side branches attached to the main limb

- viscoelastic damping: the damping effects within the tree's stem and root system

Milne (1991) studied these effects in a preliminary way and found that the sway motion in trees is damped because three main components: (1) interference of branches with those of neighbors, (2) aerodynamic drag on foliage, and (3) damping in the stem. This study estimated the importance of these three components to the overall damping was a ratio of 5:4:1 for a medium-sized tree.

The aerodynamic effects of drag have been investigated, but the mass damping influence of the sub-branches has not yet been studied. Indications of its effect have been recorded in tree cable load measurements (James 2002) and in dynamic tree movement analysis (Moore 2002).

Mass damping is a term used to describe the damping effect of a small swaying mass that is dynamically attached to a larger swaying mass in such a way that large sway amplitudes are prevented. This concept is widely used in civil engineering structures to minimize destructive oscillations (Abe and Fujino 1994). The branches of a tree constantly sway in a complex fashion that prevents large, dangerous sway oscillations being generated in the main trunk structure (i.e., they act as mass dampers in the dynamic motion of a tree). A mass damper can be represented by a mass $(m)$ oscillation on a spring ( $k$, which has some form of damping $(d)$ (Figure 1).

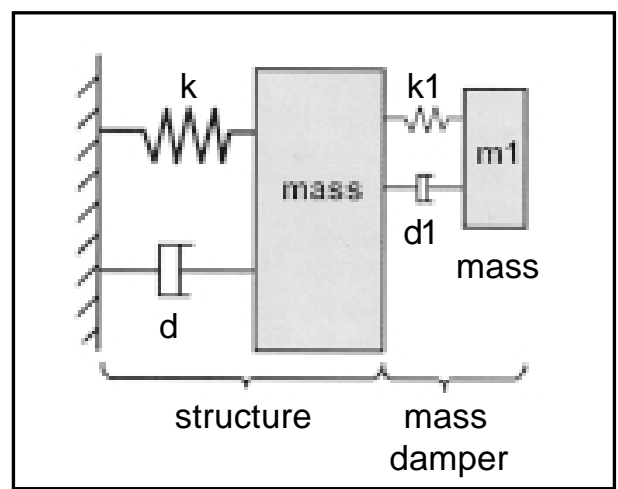

Figure 1. Model representing a mass damper, $298 \mathrm{kB} 600 \times 500-4.23 \mathrm{~cm} \times$ $5.08 \mathrm{~cm}$.

\section{DYNAMIC MODEL OF TREES}

A tree trunk swaying in wind can be considered a swaying mass $(m)$ that oscillates on a spring $(k)$ and has some damping to limit its motion (d). This dynamic model is shown in Figure 2, in which $m$ represents the mass of the main trunk, $k$ represents the stiffness, or Young's modulus, of the wood in the trunk, and $d$ represents the damping which, for a bare trunk, would consist of only viscoelastic damping of the internal wood and the root and soil mass, because there would be little aerodynamic damping due to foliage.

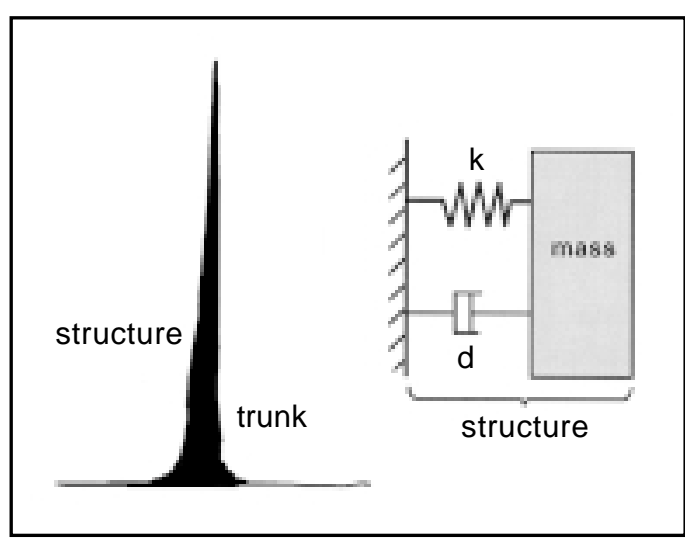

Figure 2. Dynamic model of a tree trunk (structure) represented as a mass $(m)$ oscillating on a spring $(k)$ with the motion being damped (d), $420 \mathrm{kB} 800 \times 533-4.51$ $\mathrm{cm} \times 6.77 \mathrm{~cm}$.

Figure 2 is a representation of a simple oscillating mechanism, which has a regular period of oscillation and a defined natural frequency. An example would be a pole or a pendulum. The period of oscillation is shown in Figure 3.

The natural frequency is well defined, and any oscillations at this frequency will result in large and possibly dangerous amplitudes of sway motion. It is highly desirable to avoid these oscillations in trees because these large, undamped sway motions result in large forces and energy transfers within the tree trunk structure.

The dynamic model for a tree should include the

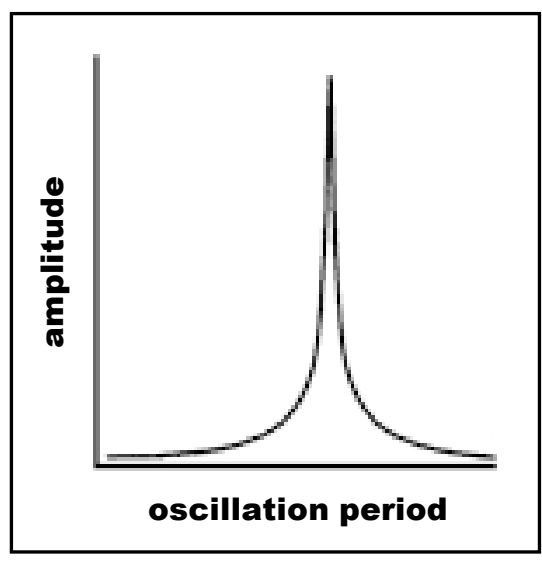

Figure 3. Period of oscillation and peak amplitude of a simple mass oscillating on a spring, $358 \mathrm{kB}$ $600 \times 603-5.11 \mathrm{~cm} \times 5.08 \mathrm{~cm}$. 
branches that are attached to the trunk, which can be represented as a smaller mass $\left(m_{1}\right)$ of the branch attached to the structure of the tree trunk. This smaller mass also oscillates as a spring of a different spring constant $\left(k_{1}\right)$ and a different damper $\left(d_{1}\right)$ (Figure 4 ).

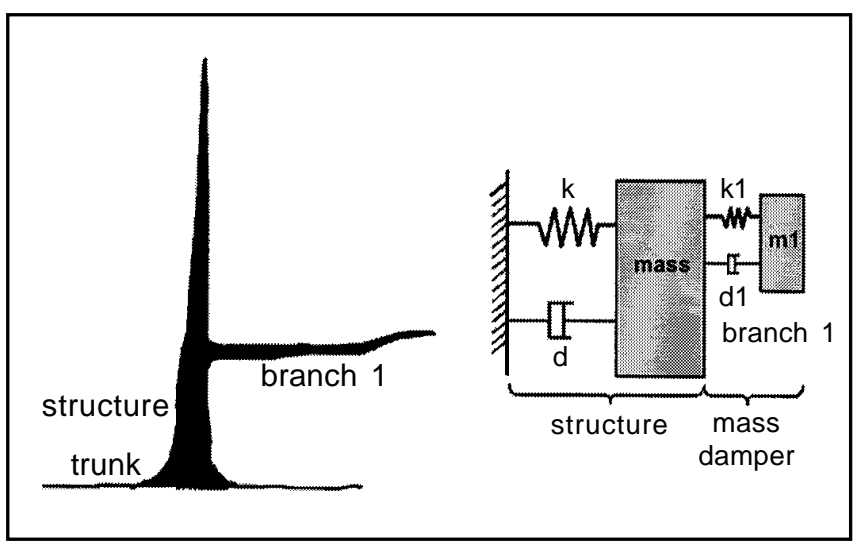

Figure 4. Dynamic model of a trunk with branch (mass damper) attached, $561 \mathrm{kB} 1000 \times 571-4.83 \mathrm{~cm} \times 8.47 \mathrm{~cm}$.

The effect of the branch on the tree trunk can be considered the same as the effect of adding a oscillating mass $\left(m_{1}\right)$ onto the oscillating structure of the parent mass $(m)$. The branch $\left(m_{1}\right)$ oscillates with a branch stiffness $\left(k_{1}\right)$, and the motion is damped $\left(d_{1}\right)$ due to leaves and internal damping.

If the branch is tuned correctly, the effect on the amplitude of oscillation of the trunk structure is dramatic. Tuning means that the branch frequency is just below the frequency of the structure. The effect is to cause a strong dynamic interaction between the structure $(m)$ and the mass $\left(m_{1}\right)$. The single frequency and large oscillation amplitude are replaced by two smaller modes, one sightly below and one slightly above the original frequency. This split mode results in greatly reduced

amplitude of sway motion. The oscillating energy of the structure partly transfers into the mass damper, which dissipates the energy through the damper $d_{1}$. The dramatic decrease in amplitude of these two split modes is shown in Figure 5.
Obviously for a tree, several main branches will act in the same way and create the effect of multiple mass dampers. This concept has been investigated in earthquake engineering literature (Abe and Fujino 1994), and the analysis uses fairly complicated mathematical techniques and matrices. As more mass dampers are added, the effect is to smooth the sway motion of the main structure even more.

Trees have many branches that need to be considered. The first-order branches are themselves mass damped with secondorder branches, which is equivalent to adding a mass damper to the first mass damper. This will smooth out the sway of the first branch. The second-order branch is also affected by smaller branches, and these smaller branches are in turn branched until a network of branches is created. These branches are represented in Figure 6 as second-, third-, fourth-, and fifth-order branches and also as equivalent mass dampers attached to other mass dampers in a cascade pattern.

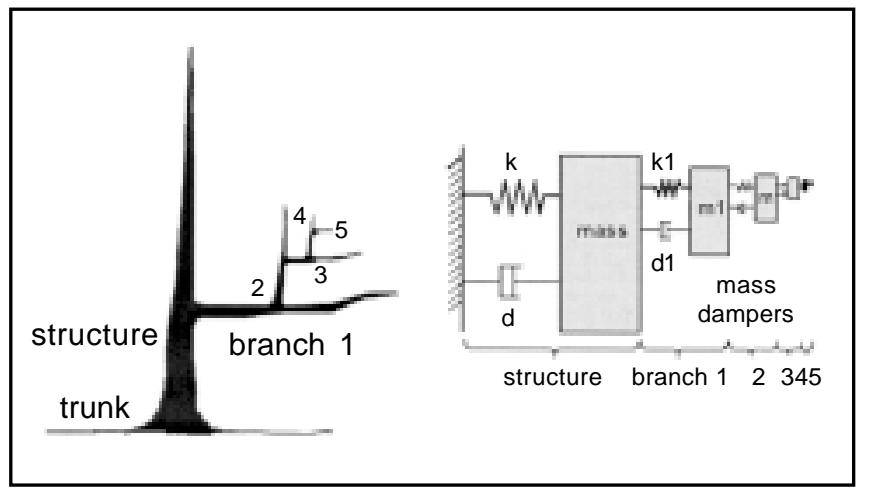

Figure 6. Complex branching of a tree and equivalent mass-damping model, $505 \mathrm{kB} 1000 \times 514-4.35 \mathrm{~cm} \times$ $8.47 \mathrm{~cm}$.

In a tree, each branch is dynamically interacting with its base branch. The mass damping model takes into account the structural and dynamic factors of each branch and the individual changes in mass $(m)$, stiffness $(k)$, and damping $(d)$.

The overall effect on the dynamic response of the tree is that a complex interaction of the branches moving creates a mass damping with a broad range of natural frequencies that smooths out the amplitude of sway (Figure 7). This prevents the main structure of the tree trunk from developing large and potentially dangerous sway motion.

An interesting study by Moore (2002) investigated the effect of removing branches from the canopies of Douglasfir (Pseudotsuga menziesii Mirb. Franco) and studied the effects on natural frequency. It was concluded that at least $80 \%$ of the crown mass needed to be removed before any increase was noticeable. This finding indicates the important influence of side limbs and that only a few branches make a significant contribution to the changes in the sway motion of a tree trunk. 


\section{MEASURING LOADS IN TREES AND BRANCHES}

Equipment was developed to measure loads on trees and branches during periods of high winds. The equipment is attached to the outer bark of the tree at various points and connected back to electronic data recording equipment. When wind creates large movement, the equipment is automatically activated and begins recording the load and movement data of the branch or trunk.

These data provide a basis for understanding the dynamic response of one tree, but many more trees need to be monitored, in different locations and through many storms, to gain enough data for predictive purposes. More work is required to investigate the size and importance of each of these dynamic loads.

The graph in Figure 8 is from the instruments that were located at the base of a branch, at the point where it was attached to the trunk of a Eucalyptus maculata. The branch is $10 \mathrm{~m}$ long and angled slightly upward from the horizontal. The wind was blowing sideways to the orientation of this branch. Shown on the graph are both horizontal and vertical loads that occurred during a wind gust over a period of $600 \mathrm{~s}$ ( $10 \mathrm{~min}$ ). The initial still conditions change as the wind gust impacts on the branch that responds with sway motion, but not like a pendulum. The branch sways in the direction of the wind but does not sway back and forth. It returns periodically to the neutral position but does not swing back toward the direction of the wind.

The largest movement is sideways, with a slight upward movement when the main gust hits at $540 \mathrm{~s}$. The branch sways in response to the wind then returns approximately to its neutral position. Further work is needed to calibrate these data into actual load data.

\section{TREE FAILURE IN WINDS}

The two major ways in which trees fail in winds are windthrow, usually in high winds, and major stem or limb failure, which may occur in either high winds or in still air conditions.

Each case must be treated separately because the nature of the failure is different. With windthrow, failure occurs at the base of the tree, where the root plate and the soil interact. There is no need to consider failure of the aboveground components of the tree structure for windthrow analysis.

With stem or limb failure, the structural components of the tree fail. The structural properties of components within the tree canopy have not been sufficient to withstand the loads they have encountered during windstorms.

\section{Windthrow}

Windthrow in a storm is caused by failure of the root plate. Several variations of the windthrow mechanism of trees are described by Mattheck and Breloer (1994). When the overturning forces of the wind exceed the resisting forces of the tree root plate, failure occurs. There is a need to measure the overturning forces of the wind as well as the resisting forces of the tree and root plate. The resisting strength of the tree to overturning is being investigated with the tree pull test reported below.

The determination of wind loads on a tree is not trivial, and there are several different estimating methods available. Many different formulas exist, usually with the tree crown treated as a sail (Mattheck and Bethge 2000). In Australia, wind loads are calculated using a method specified in the Australian Standard 1170.2 Part 2: Wind Loads (1989). This method treats the tree as a flat structure like a billboard, with some porosity, and attempts to modify wind speed using historic data by using multiplying factors for different regions, terrains and height categories, and topographic features such as hills. This method results in large values for overturning moments, which are virtually impossible to verify. It is thought that the values calculated for trees are a significant overestimate. To avoid simplifying assumptions, there is a need to measure the actual loads on trees during windstorms to obtain accurate data.

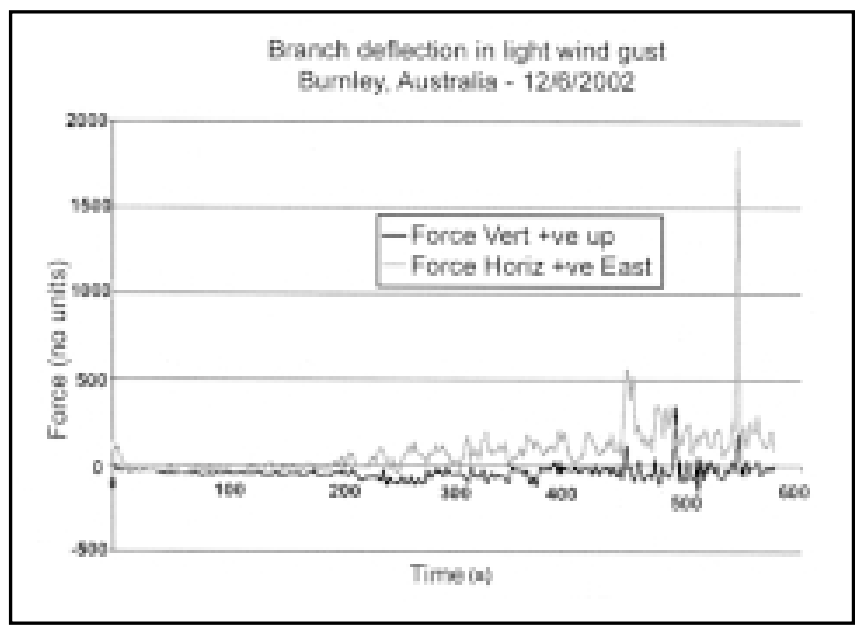

Figure 8. Sway movement of a $10 \mathrm{~m}$ branch of Eucalyptus maculata in a wind gust, June 2002, Melbourne, Australia, $700 \mathrm{kB} 1000 \times 713-6.04 \mathrm{~cm} \times 8.47 \mathrm{~cm}$. 


\section{Major Stem or Limb Failure}

A tree limb will fail when, at some point, the applied loads create a localized stress that exceeds the strength of the material. In bending, when compression and tension stresses occur on opposite sides of a cross section, the compressive forces must be examined closely because the compressive strength of wood is about half that of its tensile strength (Mattheck and Breloer 1994).

It is difficult to predict failure, and the presence of defects will greatly influence the likelihood of the failure occurring. Mattheck and Breloer (1994) provide an excellent description of outward signs on trees that can indicate hidden defects and clearly makes the point that limb failure is often unpredictable. This may be true for many types of failure, but there is a need to measure the actual loads that are applied to limbs, especially during periods of high winds. Mattheck uses the resistograph and fractometer to provide data on the internal nature of a tree so that some measurements can assist with the assessment process. In Australia, these techniques are being evaluated but are not yet widely used.

\section{PRACTICAL EXAMPLES OF APPLYING DYNAMIC ANALYSIS TO TREES Pull Test for Windthrow Evaluation}

The resistance of a tree to windthrow can be evaluated using a pull test in which a tree is pulled sideways with a load equal to or greater than the wind force. In engineering terms, this procedure is called a proof test. Pull tests conducted in Europe and Australia are providing interesting results.

A small eucalyptus tree, $15 \mathrm{~m}$ high and $200 \mathrm{~cm}$ diameter, situated in a forest in Victoria, Australia, was pulled over until it failed. The applied load was $6 \mathrm{kN}-\mathrm{m}$, which is the magnitude of the overturning moment at the base of the tree.

A tree located on a busy main road near Burnley College, Melbourne, was seen to be moving in the ground and was thought to be in danger of falling. To verify how vulnerable this tree was to overturning, a pull test was conducted. Pulling was conducted in all four directions, and a comparison was made by plotting pull versus angle of overturning. The results are plotted in Figure 9. While there was more movement in the direction over the road (as seen visibly), the test was continued until a pull of $60 \mathrm{kN}-\mathrm{m}$ was made and still the tree did not fail. This result was surprising and gave the manager confidence to make a decision to keep the tree because it was assessed as being structurally strong, though significant movement was still observed.

At a university campus of Melbourne University, Parkville, an avenue of $18 \mathrm{~m}$ plane trees (Platanus spp.) is being evaluated, and the overturning moments have been calculated using the Australian Standard AS1170.2 (AS 1989). These calculations determined that the maximum applied wind force at the base of these trees would be 600 $\mathrm{kN}-\mathrm{m}$. This is a very large figure and, based on the previous pull tests, seems to be much higher than is in fact experi- enced by the trees. Actual windthrow forces must be measured to compare real to calculated figures. At present, there is no way of knowing if the calculated values are realistic or if they are a great overestimate.

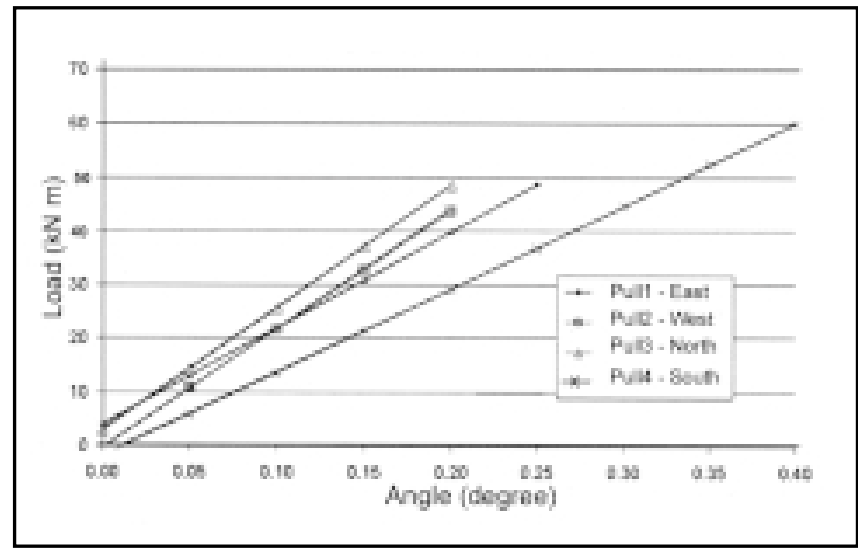

Figure 9. Pull test (in four directions) of eucalypt at Burnley College, May 17, 2000, 668 kB $1000 \times 679$ $5.75 \mathrm{~cm} \times 8.47 \mathrm{~cm}$.

\section{Tree Removal and Dismantling}

In the conventional practice of removing a tree, the arborist removes the side branches first, as he or she climbs the tree. Once near the top, the arborist ties in to the trunk and cuts the crown section, which falls away and pushes backward on the trunk as it falls. This procedure can create enough load on the trunk to cause severe and possibly dangerous swaying. The sway motion of the bare trunk does have a natural frequency, and the energy and forces developed in the trunk below the arborist may be greater than the tree would experience under natural conditions, when the side branches are attached.

The bare trunk has a natural frequency because the mass damping effect of the side limbs has been removed. Without the damping of the branches, large sway motions may occur, with associated large forces developing in the trunk. If there are hidden defects in the trunk below the arborist, the large forces generated may cause failure, with dangerous consequences to the climber.

There may be alternative removal techniques that utilize the natural energy dissipation in the tree. One idea is to leave the side branches on the tree, climb to the top section, and make the crown cut the first cut in the removal process. Doing so would prevent the trunk swaying dangerously in a pendulumlike motion and would also minimize the forces developed in the trunk. There may be practical limitations to this method, such as "hang ups" of cut sections in the canopy, but with clever rigging and more experimentation, new removal methods may develop some safer techniques that use the natural energy dissipation of mass damping. 


\section{LITERATURE CITED}

Abe, M., and Fujino, Y. 1994. Dynamic characterization of multiple tuned mass dampers and some design formulas. Earthquake Eng. Struct. Dyn. 23:813-835.

Australian Standard (AS) 1989. AS1170.2, Part 2:Wind Loads. Sydney, Australia.

Coder, K.D. 2000. Tree Biomechanics Series: Sway Frequency in Tree Stems. http://www.forestry.uga.edu/ warnell/service/library/index.php3?docID=408 (file accessed 3/28/03).

Coutts, M.P., and J. Grace (Eds.). 1995 Wind and Trees. Cambridge University Press, Cambridge, UK.

James, K.R. 2002. An Engineering Study of Tree Cables. Arborist News 11(2):35-39.

Mattheck, C., and H. Breloer. 1994. The Body Language Of Trees. HMSO, London, UK.

Mattheck, C., and K. Bethge. 2000. Simple mathematical approaches to tree biomechanics. Arboric. J. 24:307-326.

Mencuccini, M., J. Grace, and M. Fioravanti. 1997. Biomechanical and hydraulic determinants of tree structure in Scots pine: Anatomical characteristics. Tree Physiol. 17:105-113.

Milne, R. 1991. Dynamics of swaying of Picea sitchensis. Tree Physiol. 9(3):383-399.

Moore, J. 2002 Mechanical behavior of coniferous trees subjected to wind loading. Unpublished PhD Thesis. Oregon State University, Corvallis, OR.

Shigo, A.L. 1991. Modern Arboriculture. Shigo and Trees Associates, Durham, NH.

Wood, C.J. 1995. Understanding wind forces on trees, pp 133-164. In Coutts, M.P., and J. Grace. (Eds.). Wind and Trees. Cambridge University Press, Cambridge, UK.

Lecturer, Engineering

Burnley College, ILFR

University of Melbourne

Melbourne, Australia

Résumé. Les forces dynamiques sur les structures de l'arbre durant les périodes de vents forts ont été étudiées dans le but de déterminer les charges sur l'arbre ainsi que la réponse de l'arbre à ces charges dynamiques. Des mesures en milieu urbain ont été prises quant aux forces dynamiques se produisant sur les arbres, les branches et les câbles, et ce afin de quantifier la magnitude de ces forces et de fournir une base pour l'évaluation de la stabilité de l'arbre. De l'équipement a été construit in situ pour mesurer les charges dynamiques causées par le vent sur les troncs et les branches. Cet équipement est décrit. Les résultats présentés indiquent que la structure de l'arbre est chargée par des rafales de vents hautement variables et qu'elle répond en se comportant d'une manière dynamique complexe qui minimise le transfert d'énergie du vent vers les structures de l'arbre. La réponse dynamique de l'arbre implique une interaction complexe des fréquences naturelles de chaque composante de l'arbre incluant le tronc, les branches principales, les branches secondaires et les sections plus petites. Un modèle dynamique des arbres est proposé qui inclut la masse humide qui sert à minimiser les oscillations d'énergies, et ce en combinaison avec les forces de résistance du couvert pour aider l'arbre à affronter les forces des vents forts.

Zusammenfassung. Um den Lasteintrag bei Bäumen und die Antwort der Bäume darauf zu bestimmen, wurden dynamische Kräfte in der Baumstruktur während starker Winde studiert. Die Feldmessungen dynamischer Kräfte auf Stamm, Äste und Kabel bei Stadtbäumen wurden durchgeführt in der Absicht, die Magnitude dieser Kräfte zu quantifizieren und eine Basis für Baumstabilitätsberechnungen zu machen. Es wurde eine Ausrüstung entwickelt, um die dynam.

Windlasten in situ zu messen. Die Ausrüstung wird hier beschrieben und die Ergebnisse präsentiert, welche ziegen, dass die Baumstruktur belastet wird durch hochvariable Starkwinde und böen. Sie reagiert darauf in einer komplexen dynam. Art, welche den Energietransfer von Wind in die Baumstruktur verändert. Die dynam. Antwort des Baumes beinhaltet komplexe Interaktionen der natürlichen Häufigkeit jeder Komponente des Baumes, inkl. Stamm, Starkäste, Äste und Zweige. Hier wird ein dynam. Baummodell präsentiert, welches die Massendämpfung zur Minimierung der Schwankungsenergie beinhaltet und die Zugkräfte der Krone kombiniert, um dem Baum zu helfen, mit großen Windlasten umzugehen.

Resumen. Se estudian las fuerzas dinámicas de las estructuras del árbol, durante los períodos de fuertes vientos, con el fin de determinar las cargas sobre esos árboles y las respuestas a esas mismas cargas dinámicas. Las mediciones de campo de las fuerzas dinámica sobre los árboles, ramas y cables han sido conducidas en árboles urbanos, en un intento para cuantificar la magnitud de esas fuerzas, y proporcionar las bases para la evaluación de la estabilidad del árbol. Se ha construido in situ un equipo para medir las cargas dinámicas del viento en los troncos de los árboles y en las ramas. Se describe el equipo y se presentan los resultados; los cuales indican que la estructura del árbol está cargada por alta variabilidad y las respuestas por el comportamiento en un complejo dinámico. También se presenta la manera por la cual se minimiza la transferencia de energía del viento a las estructuras del árbol. La respuesta dinámica del árbol implica una compleja interacción de las frecuencias naturales de cada componente del árbol, incluyendo el tronco, las ramas principales, las sub-ramas y las secciones pequeñas. Se presenta un modelo dinámico de los árboles, el cual incluye la masa húmeda. Esto disminuye las energías de oscilación y se combina con las fuerzas de resistencia de la copa para ayudar al árbol con las grandes fuerzas del viento. 